\title{
Naturalizaciones violentas
}

Análisis de algunas paradojas existentes en las investigaciones psicológicas y sociales en fenómenos complejos como la violencia escolar ${ }^{1}$

\author{
Violent naturalizations
}

\author{
Analyzing some paradoxes in psychological and social \\ investigations dealing with complex phenomena such as \\ school violence ${ }^{1}$
}

Teresa Matus ${ }^{2}$

Proyecto FONDECYT 1040694 "Figuras estructurales de la violencia escolar: hacia una recuperación de la subjetividad educativa".

\begin{abstract}
Resumen
El argumento consiste en mostrar cinco paradojas acerca de las formas de interpretación de la relación violencia y cultura. Lo anterior es relevante ya que si se asume un posicionamiento dicotómico, la violencia vendrá siempre de los bárbaros y la civilización en cuanto cultura propondrá soluciones. Lo anterior invisibiliza que la cultura puede provocar violencia. Esto cobra especial importancia en las investigaciones acerca de la violencia escolar.

Palabras claves: relación violencia y cultura - investigaciones sociales - perspectivas epistemológicas - violencia escolar
\end{abstract}

\begin{abstract}
The argument consists on showing five paradoxes about the forms of interpretation of the relationship between violence and culture. This is outstanding since if one assumes a dichotomical position, the violence is every time assumed as coming from the barbarians and the civilization as culture will propose solutions. The above-mentioned makes invisible the fact that the culture can cause violence. This charges special importance in the investigations about the school violence.

Key words: relationship violence and culture - social investigations - epistemological perspectives - school violence
\end{abstract}

"Toda naturalización encierra un gesto de violencia. El grito de guerra que pide la integración de las ciencias es expresión de desamparo, no de progreso y se vuelve tan riesgoso y ciego como la total fragmentación" (Theodor Adorno)

Lo anterior constituye la premisa central a desarrollar. Ella busca iluminar algunas paradojas existentes en las formas de investigar el fenómeno de la violencia escolar en sus diversos ámbitos y desde diferentes disciplinas en el Chile de hoy.

1. Primera paradoja: la relevancia que tienen en los estudios sobre violencia escolar las rela- ciones entre las diversas disciplinas, como por ejemplo las existentes entre psicología y sociología. Ya que tan erróneo resultaría pedirles unificación total, como una exposición radicalmente autónoma.

Según Katz y Kahn el 80\% de las fallas de una investigación se deben a dimensiones que no se

1 Seminario sobre Violencia Escolar, realizada en el marco del proyecto FONDECYT ${ }^{\circ} 1040694$ "Figuras estructurales de la violencia escolar: hacia una recuperación de la subjetividad educativa". Facultad de Educación, 24 de enero del 2006.

2 Subdirectora de investigación y postgrado. Directora del Programa de Magíster en Trabajo Social, Escuela de Trabajo Social. P. Universidad Católica de Chile. Dra. en Trabajo Social. Universidad Federal de Río de Janeiro. Dra. en Sociología. IUPERJ. tmatus@uc.cl 
consideran en el proceso por ser "obvias". Una de ellas y tan riesgosa como el completo solipsismo de las ciencias de la sociedad y la psicología o su insistencia en factores determinantes, es la petición de su sumatoria integrada, bajo la promesa de armonizar un diagnóstico holístico sobre fenómenos tales como la violencia escolar. A esta intención responde la constitución, tanto en la investigación como en la intervención, de los denominados equipos multidisciplinarios, esos profesionales que muchas veces sólo interactúan como equipo al considerar la cercanía de sus oficinas, o en el debate acerca de la primacía decisiva de sus propios puntos de vista.

Este ensayo trata, más bien, de explorar las contradicciones existentes allí, en esos choques de lógicas entre expertos, para poder prestar real apoyo a la comprensión de fenómenos como la violencia que, de suyo, es disgregado. Tal como nos recuerda Adorno: "el éxito de la estrategia científica de Freud no deja de basarse a la postre en el hecho que en él a la perspicacia psicológica se le uniera un carácter sistemático. Mientras que justamente la intensión de forzar sus hallazgos hasta abarcarlo todo, hizo madurar el punto de falsedad al psicoanálisis, debe su fuerza de sugestión precisamente a ese afán de totalización"4.

En el caso de la violencia escolar, esa presión social por el carácter resolutivo de alguna ciencia, el encontrar el factor causal, el diagnóstico decisivo, está transversalmente colocado en padres, profesores, estudiantes y autoridades públicas. Ahora bien, si las investigaciones sobre el tema ceden a esta cohersión esperanzadora, inevitablemente se falsean. Un ejemplo, es la explicación de la violencia escolar en virtud de diversas psicopatologías, que van desde la intranquilidad constitutiva a factores de neurosis o de mayor perversidad (una especie de recreación juvenil de Linch de sus asesinos por naturaleza). Al colocarlos como síndromes, ayudan a totalizar porque aíslan el supuesto componente de predisposición frente a esfuerzos de los múltiples agentes: padres, compañeros, profesores. Incluso algunos de estos últimos, olvidaron o en verdad nunca leyeron (según su universidad de formación) clásicos como la Didáctica Magna donde, con esa antigua lucidez de los oficios, Juan Amós Commenio colocaba una regla de oro como desafío al plantear que: "la tarea del maestro es enseñarles todo a todos" mismo sentido, hace ya casi un siglo que Lukács concebía la esquizofrenia como una consecuencia extrema de la enajenación social del sujeto respecto de la objetividad. Consecuentemente, la psicología, a veces, sigue apareciendo sólo como perturbación, como patología. No es raro entonces que lo normal emerja simplemente como un sustrato residual, sobre lo cual hay poco, por inusual, que decir y los verdaderos psicólogos sean los que se dedican a desbrozar las explicaciones acerca del carácter de los violentos. Sólo que a la inversa de investigaciones como "La Personalidad Autoritaria", no se basan en las relaciones contradictorias y especulares de individuo y sociedad sino en una especie de introyección individual que emerge de la separación de los actos sociales o de la preponderancia del individuo como factor centralmente explicativo.

Entre otras consecuencias, "la separación de los actos sociales en los que se reproduce la vida de los hombres, y ellos mismos, les impide llegar a ver el mecanismo y los deja a merced de una sentencia, según la cual todo se reduce al ser humano mismo"7. De allí que se apele en algunas instancias (y en numerosas recomendaciones de estudios) a que los usuarios superen sus impulsos violentos usando, at límite, su voluntad (algo así como un llamado a liberarse de la pulsión sexual mediante el deporte). El reverso de esta recomendación, pero sustentada en la misma lógica, es una suerte de comprensión clínica, debido justamente a su tipología, transformándose en una especie científica y anticipatoria de voluntad disculpada ${ }^{8}$, ya que esas desviaciones las llevarían determinados jóvenes inscritas, al modo de una ley kantiana, en el corazón. Pero, a diferencia de Kant, no ven que ellas están allí como un imperativo colocado por la preponderancia de la regla social que se transforma en moral colectiva.

De este modo, cuando se reflexiona sobre la relación entre teoría de la sociedad y psicología, en reiteradas ocasiones no se hace sino señalar a ambas disciplinas su lugar dentro de la sistemática de las

3 Katz, Daniel y Kahn, Robert. The study of organizations. Josey Bass Publishers, San Francisco, 1982.

4 Adorno, Theodor. Escritos Sociológicos I. "Sobre la relación entre sociología y psicología” Ediciones Akal Madrid, 2004. Pág. 47.

5 Commenio, Juan Amós. Didáctica Magna. Ediciones Salamanca, 1967. Pág. 89.

6 "La hipótesis que presentamos es que las convicciones políticas, económicas y sociales de un individuo conforman a menudo una pauta amplia y coherente, cual si estuvieran unidas por una mentalidad o un espiritu común, esta pauta es la expresión de profundas tendencias de la personalidad". Adorno, Frrenkel-Brunswik, Levinson, Nevitt, Aron, y Morrow. La Personalidad Autoritaria. Editorial Proyección. Buenos Aires, 1965. Vol I. Pág. 27.

7 Adorno, Theodor. Escritos Sociológicos I. "Sobre la relación entre sociología y psicología” Ediciones Akal Madrid, 2004. Pág. 50.

8 Para un mayor análisis se sugiere revisar: Savater, Fernando. La Voluntad disculpada. Editorial Taurus, Madrid, 1997. 
ciencias y "las dificultades que plantea su relación de tratan como cuestiones de los modelos conceptuales que hay que aplicar en cada caso" Ya el propio Parsons, en el sentido trazado por Weber, percibe con agudeza "lo inadecuado de muchas explicaciones psicológicas al uso de lo social" 10 .

Por otra parte, "las Ciencias de la Sociedad y de la Psique, en la medida que avanzan sin vinculación alguna entre ellas, incurren comúnmente en la sugestión de proyectar sobre su sustrato la división del trabajo cognoscitivo"11. Si bien la separación entre sociedad y psique es falsa conciencia, como se demuestra claramente en una serie de investigaciones $^{12}$, los seres humanos no son capaces de reconocerse a sí mismos en la sociedad ni ésta en sí misma, por ello "sus relaciones cosificadas se les presentan como un ser en si"13.

De allí el peligro de interpretaciones que, por ejemplo, intentan mostrar la violencia escolar como un asunto de familia y bajas condiciones económicas donde la Escuela tendría poco que resolver. Como claramente lo coloca la directora del Programa Valoras: "Cuando un colegio atribuye a afuera lo que está pasando dentro, es un mal colegio. Un buen colegio reconoce y se da cuenta de que el fenómeno de la violencia es algo que está en sus manos"14.

También constituye un riesgo, el análisis de una serie de características de la violencia escolar asociados a actos delincuenciales, como se observa con frecuencia en los estudios de Paz Ciudadana, ya que van a reforzar un mapa donde el problema de la violencia estriba ya sea en la proximidad fatal de un mal barrio, o de una propensión psicológica del propio sujeto en cuestión. De este modo, al no considerar el que la fuente de denuncias judiciales de estos comportamientos proviene justamente de comunas de sectores medios bajos y bajos, ya que en las comunas de sectores medios altos y altos los mecanismos con que se opera con otros (llamados de atención, atención médica o psicológica espe- cializada, cambio de colegio) y sólo se denuncia en casos extremos; se reitera una oposición entre bárbaros y civilizados.

Como lo coloca en otro ámbito, prístinamente Perez de Arce a propósito de la polémica por los reavalúos fiscales: "a las comunas altas, donde gana la oposición y son habitadas mayoritariamente por gente de derecha, que en general es más civilizada....se mudan los izquierdistas cuando quieren vivir tranquilos"15. Por tanto, la seguridad no sólo es una cuestión de civilización sino de tendencia política, donde una preserva el orden y la otra impulsa el caos.

Esta línea de análisis en relación con la violencia es lo suficientemente antigua en nuestra cultura para que ya Diego Portales sostuviera que, "el principal resorte de la máquina disciplinaria era la distinción entre lo que él llama en sus cartas los buenos y los malos, aludiendo al carácter bellaco de los pipiolos, soberano obstáculo para el avance del orden"16.

Mientras que las leyes sociales no pueden extrapolarse a partir de hallazgos psicológicos, en el polo opuesto, el individuo no es un simple sustrato de la psicología sino que es siempre soporte de las determinaciones sociales que lo marcan. Las diferencias específicas de los individuos son tanto marcas de la presión social como cifras de la genética o de la libertad humana ${ }^{17}$. El asimilar el fenómeno de la violencia escolar a una cuestión de carácter, o a la distribución de golpes (el que los da, el que los recibe) de cada uno de los individuos constituye un velo social, que opaca la cadena de montaje sistémico en que ella se teje: los dilemas de la desigualdad social, el deterioro de las condiciones en que se ejerce la docencia, la re-estructuración de la educación al tornarla dependiente de los municipios en 1978, la caída de la movilidad social por la educación, de Ibañez a esta fecha; el estrellón de los sueños colectivos, la historicidad que no resiste fidelidades inhabitables ${ }^{18}$.

9 Adorno, Theodor. Escritos Sociológicos I. "Sobre la relación entre sociología y psicología" Ediciones Akal Madrid, 2004. Pág. 40.

10 Parsons, Talcott. "Psychoanalysis and the social structure". The Psychoanalytic Quarterly. Vol XIX. Número 3, 1950. Págs. 371 y ss.

11 Adorno, Theodor. Escritos Sociológicos I. "Sobre la relación entre sociología y psicología” Ediciones Akal Madrid, 2004. Pág. 41.

12 Adorno: La personalidad autoritaria, Goffman: Estigmatización y prejuicio, Horkheimer y Flowerman: Estudios sobre el prejuicio, Wieworka: Estudios sobre la xenofobia.

13 Adorno, Theodor. Escritos Sociológicos I. "Sobre la relación entre sociología y psicología” Ediciones Akal Madrid, 2004. Pág. 42.

14 Mena, Isidora. Psicóloga. Directora del programa Valoras, de la Universidad Católica de Chile. Entrevista revista YA. El Mercurio martes 21 de febrero del 2006. Pág. 28.

15 Perez de Arce, Hermógenes. "La izquierda se viene con todo". Columna de opinión. El Mercurio. Miércoles 22 de febrero de 2006. Pág. A3.

16 Góngora, Mario. Obra citada. Pág. 44.

17 Adorno, Theodor. Escritos Sociológicos I. "Sobre la relación entre sociología y psicología” Ediciones Akal Madrid, 2004. Pág. 46.

18 Respecto de la noción de fidelidades inhabitables, revisar: Guillebaud, Jean.Claude. La traición a la Ilustración. Editorial Manantial, Buenos Aires, 1995.Págs. 32 y ss. 
Así, el culto al psicologismo es el complemento a la deshumanización: "la ilusión de los impotentes de que su destino dependa de su constitución natural"19. Irónicamente, en la ciencia donde ellos buscaban individuarse como sujetos, se vuelven a transformar en objetos. Esa psicología interior (con o sin los componentes orientales que a veces la acompañan) independizada del exterior, se ha convertido en una verdadera enfermedad para una sociedad que la busca sin cesar y que está ávida por escuchar sus discursos en torno a la violencia escolar, donde se pondrá el acento en las distinciones entre individuos violentos, víctimas y testigos de la violencia. Se trataría entonces de saber contener y desplazarse entre esos estereotipos. Ante esta extendida situación en los estudios, concebida incluso como algo natural y sustantivo, cabría recordar a Nietzsche al sentenciar que "la locura es algo raro en los individuos, pero constituye la regla en grupos, partidos, pueblos y épocas"20.

Ahora bien, cuando este psicologismo se expone con metodologías analíticas se llega al verdadero paroxismo, al poder evidenciar sus supuestos con gráficos y diagramas. Allí nos llenamos de explicaciones de coeficientes, de tendencias, de probabilidades, de correlaciones, de dispersiones, de cartografías de ubicación de esos individuos en la ciudad, de sus sectores de proveniencia, de la distribución de estas patologías en colegios municipalizados y estrictamente privados. Los colores, la profusión de las impresiones, la celeridad del ritmo de la presentación (que apenas les permite a los oyentes más rápidos copiar uno de cuatro gráficos) recrea un ambiente de veracidad pseudofáctica difícil de cuestionar.

En ese núcleo de cristalización individual, las conjeturas no se hacen esperar, medidas y refutadas desde su propio patrón. La sociedad ha acuñado en él la individualización, y ésta participa en su destino como una relación social, en la que impera la maldición de la fragmentación y la ilusión de ahorrarse las contradicciones, mediante una lectura científica objetivada a través de los datos. Sin embargo, si se los observa con detención muchas de esas características de la violencia escolar, reposan sobre un soporte estructural (aunque con técnicas computacionales de última generación) que ya ha sido duramente criticado en las ciencias sociales y la filosofía contemporánea. Asimismo, es posible encontrar en algunos de esos estudios, un centro expresado en un deber ser (cómo tendría que ser un joven, una escuela, una familia) y en una especie de anillos de mayor dimensión (como al tirar una piedra en el agua) se van componiendo las diferencias en una jerarquización moral que lleva a homologar violencia con los márgenes. "El mandato freudiano donde era Ello, debe hacerse $Y^{21}$ contiene algo de vacío estoico, de falta de evidencia. El individuo ajustado a la realidad, sano-normal, es tan poco firme ante la crisis como poco económico es el sujeto racional económico. En la medida en que el sanado se asemeja a la totalidad demente, se vuelve de verdad enfermo, sin que aquél en el que fracasa la cura estuviera por ello más sano"22.

Cuando lo anterior sucede, es como si en el campo de la violencia escolar la psicología hubiese abrazado con ardor el lado de esos padres que, o bien responden con una sonrisa irónica a las ideas de altos vuelos de sus hijos, o bien confían en que la vida les enseñe modales, y que consideren más importante ganar dinero que formarse ideas estúpidas. No hay que olvidar que la teoría psicológica de los mecanismos de defensa se inserta dentro de la tradición de la vieja enemistad burguesa contra lo espiritual ${ }^{23}$.

De ese modo, como en el cine, al ver Quien quiere ser John Malkovich, el techo es bajo, y presiona a que los jóvenes se curven ante la imposibilidad de otros sueños. Sin ver esa enorme y rígida arbitrariedad, muchos de ellos, aún sin reconocerla como tal, se rebelan. Es allí, justo cuando aparece la contestación, el garabato, la respuesta altanera, el golpe, el des respeto hacia una autoridad reiteradamente no legitimada sino de facto, que se habla de jóvenes violentos y se les explica solipsistamente ya sea por mecanismos de caracterización psicológica o social. Así, las ciencias escurren el bulto frente a un fenómeno como la violencia escolar: "tratando catárticamente largo y tendido al paciente pudiente que puede pagar, al pobre, en cambio, que rápidamente ha de estar de nuevo en la arena del combate por la sobrevivencia, se le dan ciertas ayudas sociales y alguna psicoterapia breve -una división que al rico

19 Adorno, Theodor. Escritos Sociológicos I. "Sobre la relación entre sociología y psicología” Ediciones Akal Madrid, 2004. Pág. 50. 20 Nietzsche, Frederic. Más allá del bien y del mal. Aforismo 156. Editorial Alianza, Madrid 1982.

21 Freud, Sigmund. Nueva serie de lecciones de introducción al psicoanálisis. Lección 31. Volumen 15. 1944 Pág. 86.

22 Adorno, Theodor. Escritos Sociológicos I. "Sobre la relación entre sociología y psicología" Ediciones Akal Madrid, 2004. Pág. 53.

23 Adorno, Theodor. Escritos Sociológicos I. "Sobre la relación entre sociología y psicología" Ediciones Akal Madrid, 2004. Págs. 72 y 73. 
lo convierte en neurótico y al pobre en psicótico" 24 . El teatro de lo absurdo, se convierte así en realista, pues la transformación de lo social en algo interior y aparentemente atemporal lo convierte ficticiamente en lo más concreto que existe.

De esta forma, la separación entre sociología y psicología es incorrecta y correcta a la vez. Incorrecta por aceptar sin más la renuncia al conocimiento de la totalidad que ordenó esa separación; correcta en la medida en que registra la fractura, que se produce de hecho, en forma demasiado profunda como para permitir una precipitada unificación conceptual25.

Por su parte, la sociología cuanto más prescinde de los sujetos y su espontaneidad, con mayor exclusividad se debe enfrentar a un objeto cosificado, dando como resultado una sociología sin sociedad donde los hallazgos sólo dicen algo interpretados desde una ley fundamental.

La denominada sociología empírica sostiene su objetividad en los métodos, no en lo investigado. Por tanto, la posibilidad de incurrir en aporías es muy alta. Nuevamente acá, el fantasma de un sólido estructuralismo aparece reiteradamente aunque sea revestido de nuevos ropajes. Bajo la presión social, la sociología se entontece y muchas veces sólo reivindica lo siempre igual, fracasando ante la experiencia de lo específico ${ }^{26}$. Con esto la sociología le brinda en bandeja de plata a la psicología una oportunidad, ya que en la medida en que torna invariante los sucesos históricos, lo psíquico, por el contrario, se vuelve suceso histórico. De allí que justamente de estos elementos estén hechas las noticias y sus pautas editoriales, de expresiones individuales más o menos extremas (dependiendo de la época y de la competencia de narrativas) pero caracterizadas todas como acontecimientos noticiosos. Pareciera que la historia contemporánea de los telediarios estuviera constituida por dos sustratos: uno psíquico y el otro biológico. Así, entre las grandes gestas de personas, o los crímenes, o las transgresiones y las explosiones de la naturaleza (deshielo, maremotos, contaminaciones y desastres naturales, como si la acción humana en ellos fuese inocente) se perdiera una posibilidad de lectura donde los procesos y las formas de integración social hablen de una relación explíci- ta con los movimientos de integración sistémicas ${ }^{27}$. Lo anterior se concreta en la exclusión por principio de lo nuevo, en la reducción a lo que ha sido alguna vez, en una especie quijotesca de reiteración.

2. Segunda paradoja: La importancia de las formas conceptuales de interpretación de la relación violencia y cultura. Si se asume un posicionamiento dicotómico, la violencia vendrá siempre de los bárbaros y la civilización en cuanto cultura propondrá soluciones. Lo anterior invisibiliza que la cultura puede provocar violencia.

$\mathrm{Si}$, por ejemplo se coloca una estructura ideal de familia, un núcleo de orden en el centro del orden social y si esto es definido como un bastión cultural, la violencia vendrá en una relación directamente proporcional con los márgenes, y la interpretación actuará graduando la gravedad. Asimismo, si se define el hogar como lugar seguro, lo más riesgoso será la calle. Esto invisibiliza uno de los principales hallazgos en Chile en materias de violencia y género: uno de los sitios más riesgosos para las mujeres es su entorno doméstico, ya que el $79 \%$ de los casos de violencia contra mujeres ocurridas en el país los agresores no sólo son conocidos, sino muchas veces una especie de enemigo intimo ${ }^{28}$. En este mismo sentido, si la violencia escolar es una consecuencia exclusiva de factores socioeconómicos y rebeldías ante estos sistemas de exclusión social, nos quedamos sin explicación, como lo muestran García y Madriaza $^{29}$ frente a los condicionantes de esta violencia en los jóvenes de sectores altos. Siguiendo los ejes de ese argumento que cruza las relaciones de violencia y cultura, uno puede disponer de una serie variopinta de naturalizaciones:

- Naturalizaciones, como ya se expuso, de aquella psicología que se centra en patologías individuales y estereotipos, muchas veces de carácter estructural, con todo el problema que ello tiene ya que entonces surgen los violentos, así como aparecen los bárbaros, sin mayor explicación social, radicalmente construidos por su individualidad.

- Naturalizaciones de lo social: donde la violencia escolar se explica según niveles so-

\footnotetext{
24 Adorno, Theodor. Escritos Sociológicos I. "Sobre la relación entre sociología y psicología” Ediciones Akal Madrid, 2004. Pág. 76. 25 Adorno, Theodor. Escritos Sociológicos I. "Sobre la relación entre sociología y psicología” Ediciones Akal Madrid, 2004. Pág. 53. 26 Adorno, Theodor. Escritos Sociológicos I. "Sobre la relación entre sociología y psicología” Ediciones Akal Madrid, 2004. Pág. 56. 27 Habermas, Jürgen. Problemas de legitimación en el capitalismo tardío. Editorial Amorrortu. Buenos Aires, 1989. Págs. 56 y ss. 28 Informe Sernam 2002. Santiago de Chile.

29 García, Mauricio; Madriaza, Pablo. Sentido y Propósito de la violencia escolar de los cuicos. Análisis estructural del discurso de estudiantes agresivos del nivel socioeconómico alto. Revista de Psicología. Universidad de Chile. Santiago, 2005.
} 
cioeconómicos, olvidando la ya clásica oferta de desigualdad. Como expone Peña en su columna llamada Alger, el embustero ${ }^{30}$, y en la entrevista del 12 de febrero a la Nación: "nuestra educación eterniza las desigualdades ya que las escuelas están diseñadas al compás de la cuna" ${ }^{31}$. Sin embargo, los análisis de Peña se topan con la arraigada y difundida creencia en Chile que es justamente en el esfuerzo del escolar donde radica la posibilidad de éxito, en esa especie de síntesis cultural acuñada periodísticamente en la fórmula del vamos Chile que se puede, y que constituye una fuente enorme de exculpación de un sistema que debe ser claramente investigado desde bases más complejas. Donde las excepciones, que llenan las páginas de los diarios acerca de la resiliencia de algunos estudiantes provenientes de escuelas públicas o la fórmula del profesor Alquinta, no hacen más que confirmar la regla de la existencia de Chiles distintos en oportunidades y calidad de formación ${ }^{32}$.

- Naturalizaciones que provienen de los expertos en la denominada cultura juvenil, como si esto existiera en forma radical y constituyera un universo cerrado ${ }^{33}$. Donde las explicaciones se basan en supuestas particularidades adolescentes distintivas. Como si el resto de la población no estuviera propenso a la rabia, donde concretamente no se esté ni ahí con lo social en que cohabitan, como si en ese resto $\mathrm{y}$ en las relaciones fosilizadas de trabajo y expoliación no existiera la violencia, el tener que guardar silencio, como si no fueran comunes en su base, las experiencias de humillaciones de la jerarquía y de los pares. Como si la estética, la gordura, la pinta, no se convirtieran en padrón de contratación laboral. Como si en las pesadillas o esperanzas colectivas no se apareciera el mismo mercado con sus diversas estrategias de seducción. Como si la experiencia de un tiempo hamletiano, fuera de sus ejes, no tuviera como sujetos tanto a los estudiantes que ven la escuela como una rutina del sin sentido, tanto y con proporcional desventura como los cesantes ven asomarse otro día sin empleo. Como si ambos en la feliz expresión de Ciorán no estuvieran y se sintieran: caídos del tiempo ${ }^{34}$ Como si la angustia del crecimiento no dijera relación con la angustia de envejecer. Estudios donde la comprensión adquiere siempre el adjetivo juvenil como sustantivo, sirviendo éste incluso de base de comparación entre los jóvenes de hoy y los de ayer.

- Naturalizaciones de la pedagogía al confundir emancipación con orden, educación con hábitos comportamentales de disciplina, olvidando lo que es enseñar y los tabúes de enseñar ${ }^{35}$. Donde justamente el sentido político era ir contra la barbarie, procurando abrir mayores posibilidades de contingencia para todos. La escuela no se puede confundir con la familia y si en ésta última se juegan los ejes del amor y de la norma, en el colegio radican las posibilidades concretas de aprender la pasión por la lectura y la escritura y su capacidad para expresarse, elementos constitutivos y fundamentales de la identidad de cada uno de nosotros.

30 "la ideología del éxito, la idea que a cualquiera puede irle bien si se levanta una hora antes que los demás y estudia con deleite, trabaja con dureza y tiene una pizca de suerte, propagada por Horatio Alger, un escritor de novelas didácticas del que, alguna vez, se burló Mark Twain... Al contrario de lo que las historias de ese capellán enseñan, de los niños chilenos que rindieron la PSU y provienen de colegios municipalizados 37.014 no alcanzó los 475 ptos. para postular a un crédito y 30.042 no llegaron a los 450 ptos. Para postular al sistema universitario... Según lo muestra una amplia literatura -Bernstein, Bourdieu, Coleman, Jenks-, la escuela en vez de igualar las oportunidades tiende a reproducir la desigualdad".

Alger, el embustero. Carlos Peña. Vicerector Universidad Diego Portales. El Mercurio, 31 de diciembre del 2005.

31 Entrevista a Carlos Peña. Diario La Nación, domingo 12 de febrero del 2006.

32 "Me crié con muchas dificultades. Soy una prueba de que se puede". Declaraciones del profesor de Alto Hospicio, Alan Alquinta, quien ganó el concurso que Educar Chile organizó para encontrar al profesor más valorado por sus alumnos. Revista El Sábado. El Mercurio, 7 de enero de 2006. Págs. 32 y ss.

33 No se trata de plantear que en Chile no existan buenas investigaciones sobre jóvenes o que el tema de los jóvenes en la sociedad carezca de interés y relevancia. Cabe apuntar que sólo en Fondecyt existen aproximadamente 24 investigaciones realizadas en los últimos 15 años sobre jóvenes tanto en los ámbitos de sociología, psicología, ciencia política y educación. Interesantes estudios llevados a cabo por ejemplo por Ramos, Sandoval, Valenzuela, Martinic, Gili, Illanes, Serrano, Manzi, Vives; que desde diversos enfoques contribuyen a un diagnóstico más complejo del objeto de estudio. El reclamo apunta contra aquellas investigaciones que trabajan la categoría de jóvenes y cultura juvenil, con casi total prescindencia de un sentido mayor de totalidad, se trata de aminorar las posibilidades de sostener como originales ciertas manifestaciones juveniles.

34 Ciorán, Emil. El tiempo del destiempo. Editorial Trotta. Madrid, 2002. Pág. 34.

35 Adorno, Theodor. Educación para la emancipación. Ediciones Morata. Madrid, 1998. Págs. 65 y ss. 
- Naturalizaciones de los expertos en familia ${ }^{36}$, donde ella aparece como el vértice explicativo más profundo de la violencia escolar. Donde a ella se le atribuyen desde la desatención, la intranquilidad de los jóvenes, la seducción por la ingesta de drogas y alcohol, donde se asume un escenario de incomunicación como factor decisivo del desencadenamiento de una reacción en cadena que puede hacer del joven un futuro delincuente. Donde esta explicación se encuentra tan difundida y funda tanta política pública que constituye lo que Güell denomina una "sobre exigencia desproporcionada sobre la familia" ${ }^{\prime 37}$. Así, a la carga existente sobre los ya cansados padres, que muchas veces divisan los días como una carrera continua por dar respuesta a necesidades de todo orden, familiares, laborales, personales (para qué decir en aquellos que son, a la vez, padres y profesores) y que ahora son vistos como los factores causantes del problema. Algo de esto, se encuentra irónicamente dicho en la columna de Marín llamada "Moya culpable", donde resulta que después de todo, la gente es la responsable, el propio público aparece no como el afectado sino como el causante tanto del retraso de trenes, de obstáculo para que funcione el transantiago, o de la caída de diversos puentes en la región del Maule: por el uso, el uso excesivo de las vías ${ }^{38}$

En la raíz de esas naturalizaciones se encuentra el olvido de una sociedad contemporánea hecha para el dominio.

Por tanto, todo proceso de investigación social en esta esfera, tendría que considerar, de modos diversos, que la violencia opera como elemento, como manifestación, de un proceso cultural complejo que contiene rupturas y yuxtaposiciones sucesivas. Ello requiere analizar cómo la cultura, en tanto interrogante de diferenciación, contiene en sus aspectos de construcción de significaciones y espacios simbólicos, comportamientos y mate- rialidades; vínculos con formas de manipulación y distorsión, de poder e intereses fácticos.

3. Tercera paradoja a considerar: dichos enfoques dicotómicos de la violencia tienen larga data en nuestra sociedad y constituyen una especie de matriz cultural de interpretación, que divide entre "buenos y malos". Lo anterior reduce y simplifica las interpretaciones complejas al interior de procesos de intervención en violencia.

Como ya se expusiera: "para Portales, el principal resorte de la máquina era la distinción entre lo que él llama en sus cartas los buenos y los malos. Los buenos eran los hombres de orden, los hombres de juicio y los que piensan, de notorio amor al país y de las mejores intenciones. Los malos sobre quienes debe recaer todo el peso de la ley, son los forajidos, los lesos y bellacos, aludiendo sin duda a los pipiolos y los conquistadores de cualquier bando" 39 .

Dicha distinción portaliana, tal como lo señala Góngora, fue posteriormente objeto de un condicionamiento sociológico. Así, "Rengifo (quien estuvo con Portales hasta 1835) le escribe a Bulnes, ya presidente electo en 1841, que reina la paz conveniente a los grandes propietarios, los hombres amantes del orden y la tranquilidad pública, pues ya no quedan multitud de aventureros que habían pertenecido a la generación revolucionaria. Manuel Montt, por su parte, le escribe a Salvador Sanfuentes en 1845 que los partidos están reducidos a gente de frac y gente de manta" 40

Podemos sostener, entonces, que los esquemas binarios de interpretación tienen antigüedad razonable en nuestro país y que en ellos se reproduce una imagen de una sociedad con un fuerte núcleo de orden en cual se ve amenazado desde los márgenes de alteraciones a su seguridad. Está claro allí que la violencia se semantiza con la ayuda de estas visiones escindidas, haciéndolas aparecer como buscadoras de una posibilidad de emergencia y de desequilibrio del sistema social. A pesar de existir múltiples

36 Nuevamente, no se trata de hacer recaer el peso de la crítica en una generalidad de expertos, hay muchas indagaciones sobre la familia en Chile que contribuyen fuertemente a un diagnóstico más complejo, como las realizadas por Fabiola Cortez-Monroy sobre Nuevas configuraciones familiares: familias recompuestas. Revista de Trabajo Social n 71 PUC. Santiago, 2003. Págs. 141 y ss. O los variados trabajos de Teresa Valdés en FLACSO, o los aportes a la comprensión de las familias en la historia de Chile en el trabajo realizado bajo la dirección de Rafael Sagredo y Cristián Gazmuri, sobre la Historia de la Vida Privada en Chile. Ediciones Aguilar. Santiago, 2005.

37 Guell, Pedro. Informe sobre el desarrollo humano en chile. Santiago, 2002.

38 Ver la columna de Marín en el Mercurio del Miercoles 22 de febrero del 2006.

39 GONGORA, Mario Ob. Cit. pág. 44.

40 Góngora, Mario Ob. Cit. pág. 45. 
estudios como los de Espinoza sobre la Historia de los Pobres de la ciudad ${ }^{41}$, o la investigación de Ana María Stuven sobre la Seducción del Orden ${ }^{42}$, o el trabajo de Alejandra Araya sobre Ociosos, vagabundos y malentretenidos en el Chile colonial ${ }^{43}$; estas argumentaciones dicotómicas siguen teniendo la hegemonía no sólo en el sentido mal llamado común, el de las personas naturales, sino que sigue estando presente con claridad en el juicio de muchos expertos chilensis en violencia.

En el Chile de hoy también contamos con toda una suerte de imágenes duales de la violencia que no permiten pasar a un debate que devele el nexo entre sustrato cultural y violencia. Esta lógica se imbrica con la manifestación de un pragmatismo que procura una administración consensual.

Ahora bien, un punto importante es que esta lógica esencialista en lo moral coloca, por lo general, dos tipos de recursos frente a los sectores involucrados en sus juicios: o bien los califica de transgresores o si son sectores importantes de la población los coloca en riesgo, es decir, en estado de vulnerabilidad. Es así como lo demuestran diversos estudios, los 1.354.096 jóvenes chilenos hasta 24 años con que el país cambió el milenio son vistos como potencial de futuro pero también de debilidad, agresividad y fragilidad ${ }^{44}$.

Es interesante hacer notar que en el discurso público la presencia peligrosa de jóvenes se ha asociado a la delincuencia, las barras bravas del futboll, la droga, el descontrol; pero no se han dado a conocer, con la misma fuerza y publicidad por ejemplo que existen variaciones fuertes en la estructura del empleo juvenil que, como lo muestra Valenzuela han mudado en dos direcciones bien definidas, donde la primera involucra una reducción considerable del empleo obrero en el sector productivo, por lo que los cambios "llevan el signo de la proletarización y la marginalidad de los jóvenes, cuya intensidad aumenta fuera de toda comparación histórica si consideramos que tales procesos se dan en el marco de niveles de desempleo enormes para los jóvenes, sobretodo en los ochenta y noventa, que en regiones extremas llegan a más del 18\%"

En la década del noventa, más de la mitad de los jóvenes entre 15 y 19 años ocupados figura dentro de las categorías marginales de empleo y entre los 20 y 24 años el desempleo está alrededor de un 20\%, todas ellas tasas superiores en más de un tercio de las apreciadas en décadas pasadas. Sin embargo, estas variables sistémicas que afectarían una crítica al funcionamiento de la estructura económica son relegadas a segundo plano y lo que existe es una preocupación enorme por "cuidar a estas personas frágiles ${ }^{46 "}$ pero no del desempleo o la falta de oportunidades sino de la grave crisis moral que los afecta: desviaciones sexuales, apatía política, consumismo, drogas, violencia escolar. La propia noción de un acúmulo de factores de riesgo, debe ser analizada para poder desnaturalizarla.

Lo que se afirma es que hay formas de leer, de interpretar nuestros problemas que guardan una cierta lógica, que son semejantes en la manera de abordarlos y de postular sus caminos de solución, y que estos recursos binarios se transforman en una evidencia cultural.

\section{Cuarta paradoja: La importancia de los imagi- narios sociales de la violencia y la urgencia de reconocerlos como construcciones conceptuales que hay que desnaturalizar. Si prima la homo- logación del imaginario como algo opuesto a lo material, lo que ellos contengan no tendría por- qué preocuparnos, ya que es sólo simbólico.}

Existen en nuestro país una serie de imaginarios donde los violentos vienen de los márgenes, constituyendo ciertas representaciones totalizantes de la violencia. Uno de los primeros pasos para configurar esta construcción, supone achacar la violencia a determinadas personas ${ }^{47}$. Las manifestaciones de violencia se explican en este marco como una

41 Espinoza, Vicente. Para una Historia de los Pobres de la Ciudad. Ediciones SUR. Santiago, 1988.

42 Stuven, Ana María. La Seducción del Orden. Ediciones Universidad Católica de Chile. Santiago, 2000.

43 Alejandra Araya Ociosos, vagabundos y malentretenidos en el Chile colonial. Ediciones LOM, 1999.

44 Valenzuela, Eduardo. "La Exclusión de los Jóvenes". Documento de Trabajo FLACSO n²8 Santiago,1984.

45 Valenzuela, Eduardo. "La Exclusión de los Jóvenes”. Documento de Trabajo FLACSO n²8 Santiago de Chile,1984. Pág. 86.

46 Relevante resulta colocar que todo el FOSIS para el tratamiento de la pobreza está usando la denominada "Matriz Social de Riesgo", en su interpretación más liberal y que apunta ineludiblemente más a la protección que al fortalecimiento de competencias como la autonomía y la ciudadanía. En Chile nos debemos un debate serio sobre las concepciones implicadas en las teorías del riesgo y sus diversos enfoques conceptuales, así como sus repercusiones en la intervención social y en la forma que adquiere con ellas una política pública.

47 "Hay que erradicar la violencia porque es una enfermedad que en Chile tiene rebrotes agudos.

Pero no es la mayoría del país, son personas insensatas que crean una criminalidad y contra las que hay que actuar con mucha fuerza, con mucho rigor, sin vacilación”. Valdés, Gabriel. Presidente del Senado. Las Ultimas Noticias. Santiago de Chile. 19 de marzo 1991. 
forma de concebir la existencia de psicopatías diversas $^{48}$. Aún más, se puede diferenciar este "tipo de personas" como contrapartida a lo que se podría denominar "nuestra forma de ser nacional"

A esa manera de encarar el problema se le suma un efecto de dispersión. Ya no sólo caben en la clasificación aquellos "grupos violentistas" sino que la violencia tiene acá una nueva reducción a otro grupo marginal: los delincuentes. Así, lentamente se va conformando ese mecanismo del que Bentham nos porporcionará tantas imágenes: las características del encierro. Desde ya, nos habla de una suerte de exclusión renovada donde el rigor ${ }^{50}$ ocupa uno de sus lugares centrales ${ }^{51}$.

Extendiendo un poco más círculo se entra de lleno en la relación violencia-extrema pobreza ${ }^{52}$. Este temor ancestral en Chile al "bajo pueblo" ${ }^{53}$ y sus agitaciones sociales se plasma hoy, entre otros rostros, en los marginales urbanos ${ }^{54}$. Incluso al interior de las comunidades de pobladores de barrios de extrema pobreza, algunos ven una división entre "buenos y malos ciudadanos, donde se ejerce una concepción que busca propiciar una suerte de inseguridad ciudadana masiva ${ }^{55}$. Se da, por tanto, una necesidad de protección de personas que viviendo en sectores populares no comparten una perspectiva de violencia aunque por territorio les toque convivir con "los violentos".

Este enfoque, reiterado cotidianamente por algunos medios de comunicación, sirve de base a una concepción maniqueísta de describir y entender a algunos pobladores en su propio medio ${ }^{56}$.

Ampliando la espiral, otro grupo bajo sospecha en este esquema de disfuncionalidades lo constituyen, sin lugar a dudas, los jóvenes ${ }^{57}$. Incluso algunas formas de enfrentar el problema de la violencia en mensajes dirigidos a jóvenes han sido hechos con el mismo esquema de división y descalificación que se desea combatir ${ }^{58}$. Ahora bien, sin duda alguna, el debate en torno a la relación entre jóvenes y violencia alcanzó uno de sus puntos más candentes al presentar el gobierno una medida acerca de bajar la

48 "Las acciones violentas son producto de mentes desquiciadas que sólo buscan dificultar el paso a la reconciliación que el país reclama". Velasco, Belisario. Subsecretario del Interior. Las Ultimas Noticias. Santiago de Chile. 17 de marzo de 1991.

49 "Estamos en presencia de una desviación, de una violencia de lo más malsana. El atacar en la oscuridad, sin dar la cara, es algo tan opuesto a la forma varonil de los chilenos”. Martinez Busch, Jorge. El Mercurio. Santiago de Chile. 6 de noviembre de 1991.

50 Foucault, Michel. Vigilar y Castigar. Ediciones Siglo XXI. México, 1983. Págs. 58 y ss.

51 "En una sociedad sana al que delinque hay que tratar de recuperarlo y no de pisotearlo. Esto es lo que se debe educar. No se puede seguir acentuando ese rigor insensato de que si uno no quiere la muerte de los delincuentes, quiere la muerte de los carabineros. Aunque concuerdo que no existe una reinserción adecuada del preso en la sociedad, el sostener que no hay que preocuparse de los derechos humanos de los indeseables es abrir una compuerta extremadamente peligrosa de la calificación apriori de los seres humanos". Galiano, José. Abogado. El Mercurio. Santiago de Chile. 12 de noviembre de 1991.

52“En los últimos 15 ó 20 años se ha generado una concertación nacional de los sectores de extrema pobreza, que provocan y facilitan situaciones de esta índole". Conclusión seminario sobre paz y seguridad ciudadana. Comuna de la Florida, 2001.

53 Para un mayor análisis ver Violencia Política Popular en las Grandes Alamedas. Gabriel Salazar. Ediciones SUR. Santiago de Chile, 1990. Págs 52 y ss.

54 "El fantasma que hoy recorre muchas ciudades de Latinoamérica no es la imagen de la clase obrera, sino otro tanto más temible: las masas marginales urbanas empobrecidas por la crisis económica que ha golpeado a la Región durante la presente década. El caso de las 'protestas' en Santiago en el período 83/85 no fue una excepción. La 'opinión pública' y la élite dirigente chilena comparten, en definitiva, una misma sociología de la pobreza, la que tiende a vincular esta condición con una orientación a la violencia. Lo notable del caso es que no hay eh Chile evidencia empírica para sostener esta mitología violentista". Tironi, Eugenio. "Autoritarismo, Modernización y Marginalidad". Ediciones SUR. Santiago, 1990. Págs. 179 y sS.

55 "En los sectores populares del país ya prácticamente no hay un sólo hogar que no haya sufrido algún hecho de violencia desde que asumió el Gobierno de la Concertación. Es tan generalizado el pánico y la inseguridad ciudadana en estos sectores que hoy denuncian a carabineros menos del $15 \%$ de los hechos delictivos por temor a represalias". Lavin, Joaquín. Dirigente de la Unión Demócrata Independiente. El Mercurio. Santiago de Chile. 20 de octubre de 1991.

56 En estudios realizados por la Escuela de Trabajo Social de la Pontificia Universidad Católica de Chile en la comuna de La Pintana, se ha podido comprobar que dichas visiones se han encarnado profusa y masivamente, con expresiones especificas y particulares, tanto entre los dirigentes de juntas de vecinos (en la forma de describir sus problemas y caminos de solución) como en algunos jóvenes (llegando a conformar dicha distinción un eje clasificatorio) y las organizaciones de mujeres pobladoras (usando la dualidad al decidir sus acciones colectivas). Proyecto IAF. 1991.

57 "Algunos jóvenes chilenos entre 15 y 24 años tienen bajas defensas morales ante los movimientos de violencia. Diversos estudios muestran una cierta apatía e indiferencia de los jóvenes frente al fenómeno de la violencia. Esto es preocupante". Director de la Secretaría de Comunicaciones y Cultura. Las Ultimas Noticias. Santiago de Chile. 9 de junio de 1991.

58 "La campaña de los spots sobre jóvenes y prevención de la violencia delictiva es una campaña agresiva, descalificadora, que divide al mundo entre buenos y malos. Los buenos son los emisores del spot, y los malos iquiénes son?". Fontecilla, María Eugenia. Directora de la Escuela de Periodismo de la Universidad de Chile. El Mercurio. Santiago de Chile. 12 de junio de 1991. 
edad de la imputabilidad penal de 16 a 14 años ${ }^{59}$. Esto produjo encontradas reacciones. Hubo argumentos de rechazo ${ }^{60}$ e incredulidad ${ }^{61}$, pero fueron opiniones minoritarias en relación a una mayoría que apoyó la medida ${ }^{62}$. Lo paradojal es que si se analizan las estadísticas de los años sobre los que se fundó la medida, es decir del transcurso de la mitad de los ochenta a los noventa, entregadas tanto por el Servicio Nacional de Menores como por Gendarmería de Chile y las realizadas por Carabineros en la Prefectura Metropolitana observamos que es falso que la delincuencia juvenil haya aumentado ya que incluso se muestra una leve baja en los años posteriores a $1988^{63}$. Ahora bien, desde entonces hasta ahora tenemos otras cifras, que incluso muestran el aumento de la delincuencia juvenil, estamos ad portas de la creación de un nuevo Ministerio sobre Seguridad Ciudadana, pero aún nos debemos en el país un debate más profundo sobre la asociación jóvenes y delincuencia. El imaginario social generado desde hace tantos años no es impune. Un solo dato: en los presos rematados de Colina II, el 78\% de ellos tienen el triste record de haber tenido más de 22 años de intervenciones sociales en su trayectoria de vida. Las políticas públicas y los mecanismos de intervención social, no pueden, con esas cifras, reclamar impunidad. En el mismo sentido que en la reforma educacional, en el tratamiento de jóvenes y pobreza, tenemos que preguntarnos sobre quienes son los equipos a cargo de trabajar con ellos y el nivel de su competencia, así como el peso cultural de un bombardeo en la agenda pública, una presión por tolerancia cero, por esa mano dura de otros tiempos, que revisita nuestra democracia, como si esa fuera la salida. Ya que si bien, como lo demuestra Sunkel en sus investigaciones, la prensa no nos dice cómo pensar, nos coloca la agenda y el modo genérico de abordar las cuestiones tratadas.

De este modo, en la medida en que la violencia se vea personificada en personas, en grupos, en sectores etáreos o sociales particulares, en psicopatías diversas; es posible generar un efecto de diferenciación con el resto de la sociedad viéndola como una transgresión a un sistema de orden social. El problema adicional, es que este círculo concéntrico se va agrandando e involucra sectores vitales de la población que son vistos aquí no sólo como "violentos" y excluidos de recursos económicos o acceso laboral y social sino que son estigmatizados como transgresores, volviéndose doblemente víctima ${ }^{64}$. Además, si sumáramos, para tener una noción de volumen de los supuestos "disfuncionales" existentes, éstos alcanzarían más de la mitad de la población chilena.

Poniendo el acento en la responsabilidad de los "otros" vemos como la problemática de violencia

59 "Rebajar a catorce años el límite de la imputabilidad penal, extendiendo entre los 14 y los 18 la exigencia de que el juez de menores califique el discernimiento". Medida $N^{\circ} 10$ de la quince medidas anunciadas por el Gobierno el 9 de diciembre de 1991 en relación con "el problema de la violencia".

60 "Rechazo las medidas de bajar la imputabilidad penal de los menores". Organización de defensa de los niños internacional. Integrante del Consejo consultivo de la UNICEF. La Nación. Santiago de Chile. 11 de diciembre de 1991.

61 "He reaccionado con incredulidad. Ahora un niño de 14 años podrá ser encarcelado y castigado con penas de adulto. Pienso que esta medida se origina en el desconocimiento que se tiene sobre la cultura de la pobreza. Con esto se castiga más a un niño ya muy castigado: el echado de su casa, que luego abandonó la escuela, que cayó en la prostitución. Lamento que se haya puesto el énfasis en la represión y no en la prevención y rehabilitación". Avalos, Sergio. Director del Comité de Atención al Menor Encarcelado del Hogar de Cristo. La Segunda. Santiago de Chile. 10 de diciembre de 1991.

62 En los partidos políticos hubo acuerdo entre la UDI, Renovación Nacional y Democracia Cristiana sobre esta medida. El PPD la apoyó con dudas acerca del envío de menores a la cárcel y sólo el Partido Humanista y el Socialista la rechazaron.

63 Número de menores que ingresó a las unidades penales. Fuente: SENAME

$\begin{array}{lr}\text { MENORES/AÑOS } & 1985 \\ N^{\circ} \text { CASOS } & 5.532\end{array}$

$\begin{array}{rrrrr}1986 & 1987 & 1988 & 1989 & 1990 \\ 6.793 & 7.328 & 8.704 & 8.369 & 8.233 \\ & & & & \\ 1986 & 1987 & 1988 & 1989 & 1990 \\ 5.931 & 5.872 & 6.171 & 5.863 & 5.186\end{array}$

Número de menores retenidos según causales

Fuente: Carabineros. Prefectura Metropolitana CAUSALES/AÑOS

Robo

\begin{tabular}{rrr}
1988 & 1989 & 1990 \\
2.591 & 2.407 & 2.439 \\
789 & 733 & 641 \\
63 & 85 & 50 \\
41 & 45 & 29 \\
496 & 232 & 80 \\
\hline
\end{tabular}

\section{5} 4.674

64 Para un análisis mayor de este punto remito al texto de William Ryan: Blaming the Victim. Vintage books. New York. 1971. 
puede servir para confirmar la propia adhesión a un orden homogeneizante. Esta visión de "normalización" en una sociedad como la nuestra puede conllevar la imposibilidad de enfrentar nuestros irresueltos desafíos culturales por lograr una identidad colectiva que no intente suprimir las diferencias.

El nivel de pragmatismo en que se ha volcado el problema de la violencia no deja pie para adentrarse en esas tareas pendientes acerca de los procesos de identidad cultural. Esto se expresa en el plano de la discusión acerca de la violencia, haciéndola aparecer como una suerte de reivindicación donde cada fracción busca sacar los mejores dividendos políticos posibles ${ }^{65}$. Por otra parte, se sigue sosteniendo una visión reductiva de un Chile homogéneo que no tiene problemas de heterogeneidad cultural ${ }^{66}$. El superar estas reducciones y reconocer los supuestos que las subyacen implica una revisión crítica de nuestra historia y un debate abierto acerca de la forma de concebir y relacionarlos con nuestros desafíos culturales.

La permanencia de lo binario en este ámbito sería, entonces, una manifestación de los nexos no abordados entre violencia y cultura y, por tanto, una perpetuación de una causal de violencia.

Finalmente, se concluye que la forma de legitimación social de la violencia, a través de los sucesivos acercamientos binarios, pone de manifiesto una semantización del orden eminentemente oligárquico. En ella existe una apropiación del polo cultural como el núcleo del orden, de la "civilización" y éste, a su vez, presenta como límite un polo más asociado a la naturaleza, que sería el reducto de la violencia. Es claro que "la pobreza", "las etnias", "la delincuencia", "los jóvenes", pertenecerían a este extremo al que se le puede aplicar, gradualmente, la noción de barbarie. Por lo tanto, la distinción se ejerce entre el núcleo de lo humano y el de lo nohumano. Estas formas de interpretación evidencian que la diferenciación opera como mecanismo de exclusión, la "derecha" plantea un orden sin la "izquierda", el orden del sistema se logra reprimiendo lo escindido. Luego, el consenso entre perspectivas supuestamente diversas está basado en un acuerdo fundante: compartir el esquema dual de distinción. Podríamos decir, que es un acuerdo que se realiza entre iguales, donde sólo hay matices en la operatoria con el polo de la naturaleza.

Esta visión, ligada desde antiguo a la oligarquía nacional (y compartida por sectores opuestos, sólo que en una lógica invertida) nos enfrenta a un desafío radical: encontrar caminos de salida de una postura que siempre verá amenazante todo despliegue de conflicto y que, llegado el momento, legitimará el uso de la fuerza para reestablecer el orden. Allí, es imposible que en las diferencias se establezca la comunicación, aquella donde lo diferente es compartido ${ }^{67}$. Estas evidencias culturales abren un cuestionamiento a las formas asumidas por "nuestra modernidad".

En ello influyen, decisivamente, las maneras de plantearse la pregunta, las maneras de semantizar el problema. Esto se articula con los modos de concebir la razón ${ }^{68}$. Mientras se reduzca el concepto de razón a una racionalidad instrumental (planteándose, de esta forma la necesidad del retorno a la unidad valórica perdida), o se intente pasar a -lo otro- de la razón ya sea en su matriz amigo/enemigo ${ }^{69} \mathrm{o}$ en la

65 "Quien sostenga que la violencia es un problema reciente en Chile y que antes no existió, incurre en un juicio temerario y no puede sino presumirse que tan infundada aseveración busque dividendos politicos". KRAUSS, Enrique. Ministro del Interior. La Nación. Santiago de Chile. 10 de diciembre de 1991.

66 "Queremos mostrar a Chile como un sólo país: confiable, moderno y exitoso. Con una economía abierta, de gente culta. Un País de grandes consensos, con una transición exitosa a la democracia y sin grandes conflictos religiosos, políticos o étnicos. Un Chile creativo, serio, frío y apto para los negocios. Por eso el símbolo del iceberg”. MESCHI, Carlos. Gerente de Chile Expo Sevilla 92', explicando el lema de "Chile: modernidad helada".

67 ADORNO, Theodor. Sobre sujeto y objeto, en Consignas. Editorial Amorrortu. Buenos Aires, 1985. Pág. 169.

68 García, postula que a los modos de concebir la razón se asocian distintas formas de entender la relación del poder y la violencia. "Pienso que entre las tareas del presente está lograr construir una alternativa que escape al dilema cuyos cuernos son una democracia conservadora que frente a todo conflicto e intento de transformación agite el peligro de la violencia, y los proyectos que sostengan la inevitavilidad de ésta frente a una democracia refractaria a los proyectos de la mayoría". GARCIA, José Fernando. "RAZON, PODER Y VIOLENCIA EN LA FILOSOFIA CONTEMPORANEA". Colección Los Cuadernos. Universidad Nacional de Rosario. Argentina, 1990. Pág. 17.

69 "Como la concepción de política de Carl Schmitt, donde ésta se encuentra directamente referida a la crítica radical de la razón, donde el enemigo es un otro radical, existencialmente distinto, un extranjero que debe ser negado en su vida o siguiendo la terminología hegeliana, el enemigo es la 'diferencia ética'. Con el calificativo de 'existencial' Schmitt quiere indicar que en dicha relación no es posible mediación alguna, particularmente de tipo normativo. El enfrentamiento con el enemigo es inevitable, porque su simple existencia entraña la negación del propio ser. Ninguna proposición 'objetiva', 'imparcial' o 'neutra' es posible frente a la agrupación amigo/enemigo. Toda pretensión de mantenerse al margen de ella o mediar es una máscara, un disfraz que disimula una opción o un descompromiso incapaz de percibir lo esencial de la relación política. Es inevitable, pues, la participación existencial en el conflicto y no hay posible justificación a esa opción, que se fundamenta a sí misma". GARCIA, José Fernando. "RAZON, PODER Y VIOLENCIA EN LA FILOSOFIA CONTEMPORANEA”. Colección Los Cuadernos. Universidad Nacional de Rosario. Argentina, 1990. Pág. 24. 
fragmentación y transparencia de algunas posturas postmodernas $^{70}$ se vuelve difícil salir de los límites del esquema planteado, ya que, como plantea García, en aquellas versiones de la razón que significan una crítica radical a sus pretensiones o una ruptura con el mundo de la vida cotidiana, poder y violencia son coextensivos ${ }^{71}$. Para encontrar caminos de salida se requiere, por tanto, adentrarse en un concepto de razón que procure el establecimiento de mediaciones y analizar la posibilidad de gestar una sociedad más amable en una matriz cultural que se resiste a aceptar la posibilidad de una diferencia legítima $^{72}$.

\section{Quinta y última paradoja: La investigación y los procesos de intervención social son procesos de categorizaciones simbólicas, que contribuyen a la producción de subjetividades y la constitu- ción identitaria. Por tanto, si se las considera sólo como aporte en el nivel más superficial de la empiria, esa importante dimensión de con- tribución científica se torna casi invisible.}

Sin lugar a dudas, uno de los consensos en diversos ámbitos es que para intervenir en fenómenos sociales complejos como la violencia, se requiere de equipos multidisciplinarios. De allí que es necesario, pero no suficiente constituir equipos técnicos y profesionales. Hay que discutir las matrices lógicas en que cada uno de ellos ve y analiza el fenómeno:

- Así por ejemplo, si tomamos un caso de violencia escolar y al adolescente que ha sido víctima se lo lleva a un médico, no podemos pasar por alto que éste se rige por el padrón: vida/muerte. De allí que si un joven, viene caminando a su consulta es imposible para él, que le ocurra nada grave. Las lesiones, por tanto, son clasificadas desde este parámetro.

- Si el incidente tomó un carácter público y el director del Colegio lo denuncia a carabineros, ellos acostumbrados a diferenciar según las alteraciones al orden público, y a la categorización de los delitos, puede que no le concedan demasiada importancia a una denuncia que no resultara en un delito grave o a la inversa, que una pelea escolar se transforme en un asunto oficial y penitenciario ${ }^{73}$.

- Ahora bien, si el problema fue lo suficientemente grave para constituir delito, y se lo lleva a la justicia, los abogados, formados en la matriz clásica del derecho, tenderán a visualizar el problema en términos de una lógica de inocencia y culpabilidad, de víctima y acusado; lo que obstaculiza analizar más complejamente la propia constelación de la violencia escolar.

- En el caso que sea una escuela pública y de sectores bajos e intervenga un trabajador social, formado en una matriz diferenciadora de factores económico-sociales, tenderá, por lo general, a atribuir a estas dimensiones, un papel de variables causales en el fenómeno de la violencia, actuando éstos a veces, incluso como principios explicativos.

- Por otra parte, un psicólogo, dependerá de la perspectiva que asuma (gestáltico, conductista, psicoanalista en sus distintas tendencias, etc.) visualizará de muy distinto modo un fenómeno como la violencia escolar.

De esta manera, se va gestando lo que Foucault denomina, un archivo explicativo ${ }^{74}$. En el caso del

70 "Paradojalmente, la posición agresiva del postmodernismo contra la ideología fracasa en su intento por erradicar -e implicitamente postula- la perspectiva totalizante que buscaba abolir, terminando así por contradecirse. Rechaza la crítica de la ideología, pero termina introduciendo una suerte de crítica ideológica en su ataque a las metanarrativas y en sus análisis de diversos fenómenos sociales que parecen ocultar una realidad más profunda... Así, estas concepciones socavan hasta tal punto las diferencias entre al iluminismo y la manipulación, entre la verdad y la ideología, entre la razón y la dominación, que ellas mismas no pueden sobrevivir a su propia crítica". LARRAIN, Jorge." POSTMODERNISMO E IDEOLOGIA". Revista de Estudios Sociales. CPU N ${ }^{\circ} 70$ trimestre 4. Santiago de Chile, 1991. Págs 25 y 26.

71 GARCIA, José Fernando. "RAZON, PODER Y VIOLENCIA EN LA FILOSOFIA CONTEMPORANEA". Colección Los Cuadernos. Universidad Nacional de Rosario. Argentina, 1990. Pág. 27.

72 Para un mayor análisis ver: Matus, Teresa. La intervención como gramática. Revista Trabajo Social No71.

72 Para un mayor análisis ver: Foucault, Michel. Yo, Pierre Riviere... Ediciones Península. Barcelona, 1989.

72 Autés, Michel. Les Paradoxes du travail social. Editions DUNOD. París, 1999. Pág. 241-242

72 Autés esa. Cultura y violencia en Chile. Revista Persona y Sociedad. ILADES. Volumen VII N4 Santiago de Chile, 1993. Págs. 133 a 183.

73 Interesantes aportes los de investigaciones sobre violencia escolar portoriqueña, ya que en la isla, desde hace unos diez años se ha estimulado crecientemente la presencia de policías a la entrada de las escuelas, donde ellos tienen el poder no sólo de intervenir revisando las mochilas de los alumnos, sino de frenar las peleas ocurridas en los patios. En las escuelas que han asumido estas medidas la violencia escolar se ha incrementado y la autoridad de los profesores en el establecimiento ha disminuido drásticamente, convirtiéndose la experiencia escolar en una experiencia de lidar con los códigos policiales.

74 Para un mayor análisis ver: Foucault, Michel. Yo, Pierre Riviere... Ediciones Península. Barcelona, 1989. 
parricidio de Pierre Riviere, Foucault yuxtapondrá los discursos médicos, de la prensa, de los legisladores, de la familia, de los vecinos, los diarios escritos por el propio Riviere en la cárcel, preguntándose cómo trabajar con esas lógicas que chocan diversa y desigualmente. Lo anterior es muy importante para que las personas que acuden a estos servicios, que ya han sido afectadas por un incidente de violencia escolar, para que no sean doblemente maltratadas por un sistema de intervención contradictorio. Asimismo, los usuarios tienen derecho a saber desde qué enfoque van a ser vistos y cuál es la posibilidad de una intervención exitosa

Ahora bien, si la categorización social se realiza en términos estigmatizadores, esos sujetos llevarán esa marca en forma persistente. De allí que estudiar los modelos de investigación e intervención social enfatizando su potencial simbólico-enunciativo, resulta clave en el logro de mayores oportunidades de equidad y desarrollo de la ciudadanía. Se podría sostener que algunos adolescentes han sido doblemente víctimas en el sentido en que no sólo se han involucrado en un episodio de violencia escolar, sino que han estado aprisionados por los límites y los choques de las lógicas de los expertos que no logran comprender de qué se trata ni las motivaciones y argumentaciones de los propios involucrados, ya que su sentido más hondo se les escapa. Cuando un profesor ve llegar a un estudiante a la inspectoría y cree que ya sabe quien es y de qué se trata, es decir, tiene ya una opinión formada antes de escuchar, el resto transcurre, como en García Marquez como la crónica de una muerte anunciada.

En este sentido, tal como expresa Autés, trabajar lo social es una práctica simbólica y su eficacia es de naturaleza simbólica ${ }^{75}$. Sin lugar a dudas, esa sentencia expresa un giro en la forma de pensar el sentido y la función de la investigación y la intervención social. Para entender su contenido, sin embargo, se requiere no tratar lo simbólico ni como opuesto a lo real o lo material, ni simplemente como gesto emblemático ${ }^{76}$. Por el contrario, lo simbólico acá se inserta en el cruce, en la mediación interpretativa de todo lo real ${ }^{77}$. Así, él se encuentra implícito en toda acción social y precisa ser develado en su construcción. De allí que desafía a los equipos a dejar su lenguaje de exterioridad para deconstruir sus premisas. Aquí aparecen dos claras demandas: develar los mecanismos epistémicos y socioculturales en los que se inserta su quehacer y colocar los enfoques éticos no por fuera o reducidos al profesional, sino como parámetros, como indicadores operativos específicos en sus modelos de investigación social.

Lo anterior tiene como sustrato el entender que ejercer el oficio de investigador conlleva un ejercicio de representación, ya que allí se representa y se vuelve representación a esos otros que se nos aparecen con su carga simbólica a cuestas. El "otro" ha sido fuente de un riquísimo imaginario sociocultural poblado de visiones amigables o amenazantes. Desde la idea "otro natural" intrínsecamente bueno a un sujeto que poco a poco se pervierte en el contacto socie$\mathrm{tal}^{78}$. Toda la noción de civilización y barbarie radica en la distinción de la idea de otro ${ }^{79}$.

La cuestión acá es que "el otro" adopta las características dada por quien lo mira y lo busca nombrar ${ }^{80}$. Y si bien a un otro, subornidado, jerarquizado, se le puede conceder alguna virtud estética o moral, muy difícilmente se le otorgará un estatuto de legítimo pensamiento. Se podría plantear que, guardando las distinciones, estamos en presencia de una semántica que conforma una tipología, un tipo de representación social de la pobreza que está inscrita en el corazón de esos mecanismos que generan, como va a plantear Geremek: "a los hijos de Caín". Que crea una especie de tautología simbólica, al encadenar

\footnotetext{
75 Autés, Michel. Les Paradoxes du travail social. Editions DUNOD. París, 1999. Pág. 241-242.

76 Autés, Michel. Les Paradoxes du travail social. Editions DUNOD. París, 1999. Pág. 243.

77 Freynet, Marie-France. Les médiations du travail social. Chronique SocialLyon, 1999.

78 Rousseau, Jean Jacob. "El Contrato Social”. Editorial Alianza. Madrid, 1974. Págs. 33 y ss.

79 Toda la tematización en la conquista de América que hace Todorov se encuentra permeada por la idea del indio como "otro": "No sólo las coordenadas temporales, también las espaciales quedan descentradas. El encuentro con el indio-el otro- plantea una nueva escala de diferencias que cuestiona de inmediato la propia identidad". Todorov, Tzvetan. "La Conquete de L'amerique. La Question de L'autre". Editorial Seluil Paris, 1982. Pág. 25.

80 "Los salvajes se vuelven para los psicoanalistas aquella escena primordial de la que derivan la Ley y su Palabra, los estructuralistas los convirtieron en una especie de computadoras silvestres dedicadas a reproducir inacabablemente su ingenioso juego de permutaciones, con el único pie forzado del tabú del incesto; los marxistas descubrieron en ellos encubiertos conflictos de clase, un ensayo general de la tragedia dialéctica pro venir, hallando asi pruebas inequívocas del mágico motor de la historia que ronronea incansable desde los albores del mundo; y los religiosos descubrieron en ellos, por supuesto, santos y pecadores. Lo cierto es que los salvajes disminuyen, pero las interpretaciones se multiplican".

Savater, Fernando. "El Buen Salvaje y el Mal Anarquista”. Editorial Alianza. Madrid, 1986. Pág. 142.
} 
las evidencias de la disconformidad de la pobreza con un cierta cosmografía de la anti-sociedad, donde lo amenazante convoca a toda clase de personas pobres, enfermos, vagabundos, pícaros, delincuentes $^{81}$. Una especie de nave de los locos, pero ya sin las interpretaciones de la miseria como un accionar profético del verdadero sentido de la vida, propio de los comienzos de la Edad Media ${ }^{82}$. Así, no es sorprendente que este tipo de interpretaciones llenen sus manos de cosechas de anti-sociales y que su solución, en la mayoría de los casos alterne garrote y zanahoria, represión y ayuda, conmoción por las circunstancias y formas de vida de los miserables, pero a la vez, una sensación creciente de amenaza social. Dicho de otro modo, desde esta expresión de un régimen de la mirada sobre el otro, se construyen una serie de imaginarios socioculturales ${ }^{83}$.

Así, mediante los procesos de investigación, se genera un dispositivo de enunciación que controla, que restringe o que emancipa, que empodera, que contribuye a fortalecer el capital social ${ }^{84}$. Consecuentemente, la investigación es una actividad simbólica que renueva la acción social mediante una resignificación de los imaginarios sociales que se dan en el mundo social. Dicho en otras palabras, opera en la producción de subjetividades, en la construcción de identidades, en la reconstrucción de los lazos sociales. Élla inscribe al sujeto en un sistema de relaciones. Por su acceso a la palabra, a la capacidad de enunciación, produce existencia social, sobredeterminando sus propias prácticas ${ }^{85}$.

Se trata entonces, de comprender una vez más y entender que incluso todo dato cuantitativo, se coloca y cobra vida al interior de un horizonte referencial herméutico, de otro modo, no sólo la subjetividad reflexiva de los involucrados no se recupera en las investigaciones, sino que a la propia violencia escolar se la estudia, paradójicamente, desde naturalizaciones violentas.

FECHA DE RECEPCIÓN: enero 2006

FECHA DE ACEPTACIÓN: marzo 2006

81 Geremek, Bronislaw. Os filos de Caim. Editorial Companhia das Letras. Sao Paulo, 1995. Págs. 302 y ss.

82 Gurvitch, F. Las categorías medievales de la pobreza. Editorial Península. Barcelona, 1999. Pág. 6.

83 Como el sinnúmero de recreaciones sobre "los otros" que muestra Eco a través de Superman, el gatopardo de Malasia, la idea de servicio a los otros, la modelación de las exigencias del otro en los sectores medios, el rechazo del intelectual o la conciencia cívica como vigilancia de los otros. Eco, Umberto. "Ni Apocalipticos Ni Integrados". Editorial Lumen. Barcelona, 1993.

84 Para un mayor análisis de la relación Cultura-Capital social se remite a: Klisberg, Bernardo y Tomassini, Luciano. Capital Social y Cultura. Claves estratégicas para el desarrollo. Fondo de Cultura Económica. Buenos Aires, 2000.

85 Como ya lo sostenía Foucault: El discurso contiene un potencial de vida y de muerte. Foucault, Michel. EL orden del discurso. Editorial La Piqueta. Barcelona, 1997. Pág. 4 y ss. 